\title{
DISTINCT APPROACHES TO VALUE SYSTEM IN COLLABORATIVE NETWORKS ENVIRONMENTS
}

\author{
Patrícia Macedo, Claudio Sapateiro, Joaquim Filipe \\ Escola Superior de Tecnologia de Setúbal \\ Instituto Politécnico de Setúbal,PORTUGAL \\ 'pmacedo@est.ips.pt, ${ }^{2}$ csapateiro@est.ips.pt, ${ }^{3}$ iffilipe@est.ips.pt
}

\begin{abstract}
For several years, Value Systems have been studied by two distinct scientific disciplines: economy and psycho-sociology. Each discipline developed a different concept of Value System, based on distinct assumptions about value. On one hand, economists assume that value means how much (usually money) a product or service is worth to someone, relative to other things; on the other hand socio-psychologists define value as shared beliefs on morallethical principles of the organizational unit.

This paper presents a contribution in the study of Value Systems in the context of collaborative network organizations (CNO). The work based on M. Porter's approach applied to CNO is analyzed and related modeling techniques to represent an economic Value System are presented. A similar analysis is presented regarding the axiological perspective from socio-psychology, including the description of possible modeling techniques, in a CNO context. The aim of this paper is to compare these two approaches to Value Systems in the CNO context and to conclude about their relevance in the setup and management of this kind of organization.
\end{abstract}

\section{INTRODUCTION}

In the last years, studies conducted in collaborative networks area have shown that some requirements are needed to create collaborative coalition: share goals between members, have some level of mutual trust, had create some common infrastructures and had agreed totally or partially in some practices and values (Afsarmanesh, 2005). In order to be able to create a dynamic collaborative network, mechanisms to make both the selection of partners and the set-up of the network more agile must be developed. The definition and representation of the Value System of each member of the network can be an important tool to network management through its lifecycle.

For several years, Value Systems have been studied by two distinct scientific disciplines: economy and psycho-sociology. Each discipline developed a different concept of Value System, based on distinct assumptions about value. On one hand, economists assume that value means how much (usually money) a product or service is worth to someone, relative to other things; on the other hand socio- 
psychologists define value as shared beliefs on moral/ethical principles of the organizational unit.

Social sciences consider Value Systems as the ordering and prioritization of the ethical and ideological values that an individual or society holds. Values can be classified in communal and individual. Communal Value Systems are applied to a community or society, and may be supported by a legal set of laws and norms.

Economists defend that a Value System describes the activity links between the firm and its suppliers, other businesses within the firm's corporate family, distribution channels and the firm's end-user customers (Porter, 1985). Nowadays the Porter's system-value concept is generally used by managers and economists in enterprise strategic and operational management. Several informatics applications have been developed to address this issue, where supply chain managements systems (SCM) are well known.

Axiology is a general theory/science of human values, their origins, interrelations and dynamics The philosopher Robert Hartman (Hartman, 1973) is the father of formal axiology, which is a branch of axiology that attempts to use mathematical formalism to define values and Value Systems. There are diverse application studies of Psycho-socio Value System in several scientific areas, as: Education (Cooley, 1977), Organizational Management (Krishnan, 2005) and Information System Design (Shneiderman, 1998) (Goguen, 2004)

Several authors have referenced the Value System topic in their collaborative network studies. Some authors use Value System in its economic perspective (Katzy, 1998) (Liu, 2005) (Tan, 2004) (M.Jamieson, 1986) (Camarinha-Matos, 2005) (Gordijn, 2000) others in a more sociological and ethical approach (Filipe, 2003) (Afsarmanesh, 2005) (Rezgui, 2004).

This paper presents a contribution to the study of Value Systems in the context of collaborative network organizations (CNO). The aim of this paper is to compare the two approaches to Value Systems in the CNO context and to conclude about their relevance in the setup and management of this kind of organizations. The next section presents the economic approach to Value System where the work based on M. Porter's is analyzed and related modeling techniques to represent this Value System are presented. A similar analysis is presented on section three regarding the axiological perspective from socio-psychology, including the description of possible modeling techniques. In section four the application of these concepts of Value System in a CNO context is discussed. Conclusions and future work are present on section five.

\section{ECONOMIC APPROACH TO VALUE SYSTEM}

\subsection{Overview of Porter approach for Value System}

To understand Porter's Value System concept, two other related concepts are required: Value Chain and Value Activity.

- The value chain categorizes the generic value-adding activities of an organization. The value chain shows total value and consists of value activities and margin. Company activities can be represented in a value chain that should draw at the business-unit level (Porter, 1985) 
- The value activity is an activity performed by the organization which is technologically and strategically distinct from any other. Activities are classified in primary activities and support activities. Primary Activities includes: Inbound Logistics; Operations; Outbound Logistics; Sales and Marketing; and Customer Service. Support Activities include: Firm Infrastructure; Human Resource Development; Technology Development; and Procurement. (Porter, 1985)

In Porter perspective a Value System can be used as a tool to analyze how a company positions itself relatively to other companies. A Value System shows the role of a company in the overall activity of providing a product to a customer. The Value System makes explicit who are the suppliers and what are the channels of the given company. It allows understanding if all the companies involved in the sale process are truly collaborating or if they have conflicts of interests. It also allows comparing a company with its competitors. (See Figure 1 for the illustration of the relationship between value chain and Value System).
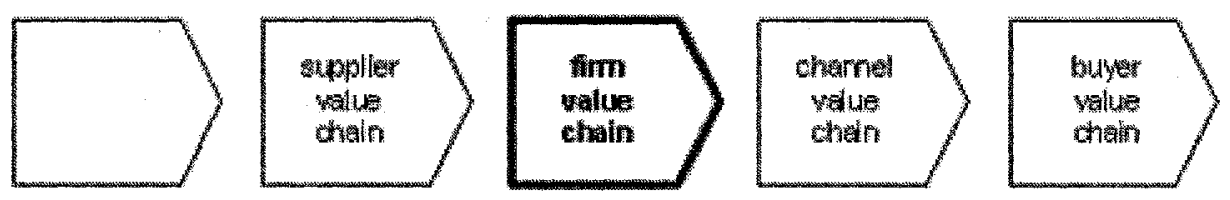

Figure 1 - Value System (Porter, 1985)

\subsection{Extended Porter Value System Concept}

The concept of value added activity can be applied not just to an economic value. The mission of some Organizations is not to win economic value, but other kinds of rewards, as: reputation, power and influence; belonging and membership; quality improvement, knowledge.

When the goal of an organization is not to increase economic value, it is necessary to define a way to measure value, in order to evaluate the value added. To each kind of value a unit of measure needs to be associated.

Gordijn, Yao-Huan Tan and Kartseva in his work (Gordijn, 2000) (Tan, 2004) (Kartseva, 2004) about Value Systems has introduced the concepts, of value object, and value activity. A value activity is performed by an actor to produce objects of value by adding value to other objects of value. They define an actor as an independent entity that adds value to the system doing value activities. An actor can be an economic or and legal entity that engage in business transactions. Actors and value activities exchange value objects. A value object is a service, thing, or consumer experience that is of value to one or more actors. A value object has one or more valuation properties. Such a property has a name and a unit that indicates the scale in which the object is evaluated. 


\subsection{Modeling Value Systems (economic approach)}

Modeling a Value System as describe above implies to be able to describe the sequence of activities that support the Value System, the value object and the actor.

To this purpose we analyze some known techniques commonly applied to process modeling. In a Value System model, resources and activities that not add value are not represented; just value activities and value object are shown. With respect to modeling processes or activities concerning the Value System we can use/adapt several of the existing proposes is processes modeling. One of the most popular is UML. UML diagrams had the advantage of visual/graphics orientation which is easily to adopt/understand and promotes the communication between interested parties without the need of in depth technical skills. However the consistency of the model across all its diagrams and the correctness achieved when transposing from modeling to design is still worth some attention because UML provides only a semi formal approach without sound semantics.

Another approach in process modeling that could be used in Value Systems is graph theory (Krebs, 1998). Graph theory is a branch of mathematics concerned with how networks can be encoded and how their properties can be measured. The main goal is to represent a network in symbolic terms, abstracting reality as a set of linked nodes. Typically, nodes represent objects/resources/people/technologies and the links the connections needed to achieve some goal. In the Value Systems context this network can represent activities flows and ones can have different nets, concerning different perspectives of the system. We can also associate costs to the links between nodes allowing the evaluation of a cost function to some flow. An extension of graph theory respecting to social relationships is the Social Actors Network theory (SAN). SAN are a way to highlight the structural relationships among social actors providing a conceptualization of their interactions in a systematic way. SAN had available metrics that allow interpretation of the kind/depth of connections presents in the net. (Soares, 2005)

Yet other approach that could contribute to model Value Systems are those based in Petri Nets (Aalst, 2001). The Petri nets based approaches have been used with success in modeling dynamic systems of discrete events characterized by parallelism and synchronization needs. If ones consider the Value Systems described in the previous section ones can establish the parallelism with the Petri nets mechanism: an activity takes place in the presence of some pre-conditions and/or inputs and will produce some post-condition and/or outputs. The usual main motivations to the use of this approaches is due to the fact they are based in a strong mathematics foundation and so they had available several analysis tools. These tools permit the inspection of several behavioral and structural net properties. Some of these tools/properties may be used to verification of the net (context independent ones) and others are used to net validation (context dependent ones). Also they had a visual/graphical orientation which has the advantages already pointed to UML but unlike UML in the Petri nets case we create precise formal models. There are some extensions like colored Petri nets which may assign several attributes to each node in the net, or Petri nets with costs parameters in order to evaluate some cost function. 


\section{SOCIO-PSYCHOLOGY APPROACH TO VALUE SYSTEMS}

\subsection{Axiological systems}

Socio-Psychology in general considers a Value System as a set of principles and values common to a group of people. According to social theory, principles, laws and values are types of norms. Norms can be classified as perceptual, evaluative, cognitive, behavioral (Stamper, 1996). The different types of norms reflect the different aspects that a social system can share, as perception, interpretation, cognition and behavior.

- Perceptual norms are associated to the attitude of acknowledge the existence of something - Ontological attitude.

- Evaluative norms are associated to the attitude of being disposed in favor or against something in value terms - Axiological attitude.

- Cognitive norms are associated to the attitude of adopting a degree of believe or disbelieve - Epistemic attitude

- Behavioral norms are associated to the attitude of being disposed to act in some way - Deontic attitude.

The philosopher Robert Hartman developed formal Axiology, that is a branch of axiology (axiology is a general theory/science of human values, their origins, interrelations and dynamics) that attempt to use mathematical formalism to define values and Value Systems. Hartman (Hartman, 1973) first defined the concept of value in terms of a logic-based axiom. This axiom is that value can be objectively determined according to a one-to-one correspondence between the properties of a given object and the meaning specifications contained in its concept. An object has value to the degree it fulfils its concept. (Mefford, 1997) Hartman introduced also the concept of Dimension of Value and developed the basic axioms through this concept. He defines three dimensions for value: Systematic Value, Extrinsic Value and Intrinsic Value.

- Systematic Dimension - The dimension of formal concepts. Ideas of how things should be. This dimension is the one of definitions or ideals, goals, structured thinking, policies, procedures, rules and laws.

- Extrinsic Value - The dimension of abstracting properties, comparing things to each other. This is the dimension of comparisons, relative and practical thinking

- Intrinsic Value - The dimension of uniqueness and singularity. This is the dimension of uniqueness, of person or things as they exist in themselves. There is no comparing.

Hartman defends that the foundation concepts of axiology provides the framework for understanding an object's value and valuations of it, in precise terms of the three dimensions and their relation to each other.

Goguen et Linde have developed since 1978 several studies about value and Value System in organizations (Goguen, 1994, Goguen, 1997, Goguen, 2004).They have developed a method for using discourse analysis to determine a Value System for an organization from a collection of stories told by members of the organization 
among themselves on informal occasions. The evaluative material collected from the stories is classified and represented using a formal structure called a Value System tree. A Value System tree (Goguen, 1994) serves as a formal summary of the interpretation that the analysts had made from the data that has been collected.

Another contribution to the study of values systems came from Distributed Artificial Intelligence discipline. This discipline has developed some theories about Value Systems using agents. (Filipe, 2003) proposed an approach based on organizational agents where is assumed an agent is responsible for its values. The agent's preferences with respect to norms are defined in its Value System. In this approach an agent can represent a member of an organization or an organization itself.

\subsection{Modeling Value Systems ( socio-psychological approach)}

Value System trees, proposed by Goguen (1994), can be modeled and represented using the UML standard, through a class diagram. Another possible approach to model Value System tree it's Prioritized Modal Default Logic (Brewka, 1994), that allows defining the order of values. Modal logic is an extension of ordinary logic and is concerned with logical facts that involve qualifications of propositions.

Formal methods have the advantage of making the conversion to computer programs easy, when compared to languages with graphical notation, such as UML. For the purpose of communication and analysis these kind of languages are more suitable.

Hartman in its works on Formal Axiology have proposed a formal representation for value and for Value Systems based on algebraic mathematic. Some semiotic studies also introduce a formal way to represent the Value Systems based on algebraic theory (Goguen, 1999)

The approach based on agents suggested by (Filipe, 2000), where attempt to model the Value System of an agent (its axiological component) propose the use of default modal logic (Reiter, 1980).

The approaches to modeling socio-psychological Value Systems describe above apply essentially formal methods developed in Computer Science. Formal modeling approaches, as formal axiology, modal default logic and algebraic semiotics are used in order to specify the order and prioritization of the ethical and ideological values

\section{POTENTIAL APPLICATION IN CNO CONTEXT}

In the last two sections distinct approaches to Value System were presented. In this section it is discussed the applicability of each in the CNO context.

The original purpose of a value chain was to identify the fundamental valuecreating processes involved in producing a product or service within a firm, the concept has since been used to describe an entire network (Bouwman, 2003).

Evans (Evans, 2004) classifies collaboration in networks as:

- Goal-driven - where the objective is to deliver something (product or service) within stated time, cost and quality goals. 
- Capability-driven - where the objective are improve personal capability, or knowledge sharing. (examples: Linux community and IEEE )

It's relevant to understand which activities add value to the network and which member contributes with it. The values considered in a goal-driven network type are different from capability-driven networks. (Afsarmanesh, 2005)In order to evaluate the values added by one activity to the network, it have to be defined how the specifics values could be measure. Tom Gilb developed methods and techniques to measure Software quality attributes (Gilb, 1989). His work contributes to the development of measurement technique of social issues. Directly related to Virtual Organizations, (Camarinha-Matos, 2005) exemplify a way to combine values with different scales in order to evaluate the benefit of a collaboration.

Table 1 - potential application of Value System for management through life-cycle

\begin{tabular}{|c|c|c|}
\hline $\begin{array}{l}\text { Life- } \\
\text { Cycle } \\
\text { Phase }\end{array}$ & $\begin{array}{c}\text { Economic Approach of Value } \\
\text { System }\end{array}$ & $\begin{array}{c}\text { Socio-Psychologist Approach of } \\
\text { Value System }\end{array}$ \\
\hline$\frac{1}{3} \stackrel{0}{\frac{d}{2}}$ & $\begin{array}{l}\text {-Simulate several scenario of Value } \\
\text { System in order to decide for the best } \\
\text { scenario. } \\
\text {-Select partner that can contribute to the } \\
\text { Value System. }\end{array}$ & $\begin{array}{l}\text {-Partner selection - helps to select partner } \\
\text { with Value Systems that not collide, helps } \\
\text { to select partner that best fit in the network. }\end{array}$ \\
\hline हू है & $\begin{array}{l}\text {-Define the exact contribution of each } \\
\text { partner to the Value System }\end{array}$ & $\begin{array}{l}\text {-Definition of norms to operate the CNO. } \\
\text { Value System will provide tools to define } \\
\text { norms and to detect possible conflicts } \\
\text { between member norms and CNO norms. }\end{array}$ \\
\hline 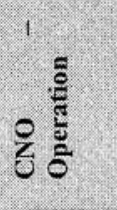 & $\begin{array}{l}\text {-The Value System model it's the base } \\
\text { tool for planning activity. } \\
\text {-Value System model can be used to } \\
\text { monitories performance. }\end{array}$ & $\begin{array}{l}\text {-Solving conflicts between CNO members. } \\
\text { Detecting easily which set of norm it's } \\
\text { causing the conflict. } \\
\text {-Improve relationship between members. } \\
\text { Permit to identify the set of priorities values } \\
\text { of each member and act according it. }\end{array}$ \\
\hline 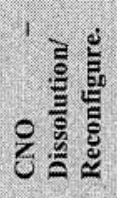 & $\begin{array}{l}\text {-To plan reconfiguration, allow the } \\
\text { study several Value Systems scenarios }\end{array}$ & $\begin{array}{l}\text {-Select new partners adjust some norms of } \\
\text { operation. }\end{array}$ \\
\hline
\end{tabular}

The definition and representation of the Value System (economic approach) in a collaborative network have a set of distinct applications in network life-cycle management. It can contribute to the selection of partners that can increase the value of the network. It permits the calculation of the value contribution of each partner. 
Value System model can also be used to monitories performance and to plan operational activities.

Values are the essence of what holds communities together (Goguen, 2004), so to choose partners its very important to analyze their core competencies and their coherence with the network strategy .Another important criterion is the amount of effort needed to coordinate and integrate them (Wiendalh, 2002). The definition of Value Systems (socio-psychological approach) will help to understand if Value System of a partner will fit the Value System of the CNO. In order to avoid conflicts, it is important to identify candidate's conflicts points and determine the possible collision between member's internal norms. Another potential of application for Value System is on the member's relationship improvement, by the identification of the set of priorities values in order to act according it.

The potential application of each concept for Value Systems in CNO was analyzed. This analysis is resumed on table 1 , where the distinct contributions of each approach for Value System are shown.

\section{CONCLUSIONS}

Both perspectives of Value Systems (economic and socio-psychological) are relevant to performance management in collaborative networks, as was shown in section above. The analysis presented on table 1 allows us to conclude that these two perspectives of Value Systems are complementary. In essence the Economic perspective provides a transaction mechanism between partners, and the psychosocial perspective provides a regulation mechanism to ensure social cohesion, to avoid and solve conflicts and to build performance indicators.

The definition, representation and application of Value Systems to Collaborative Networks it is a challenging area of research. The main questions that were identified to drive research in this field are:

- How to create a conceptual model that integrates these two approaches of Value System?

- Are there different types of values? Which types?

- A value can be represented as an object? In this case which are the attributes that characterize an object value?

- A system is a set of elements and the relation between them. How to define the functions of relation between elements? Can we apply system theory and classify the relation structural, hierarchical (composition and specialization) and behavioral relations? How to define value priorities inside the system?

- What is the relation between Value System and system of incentives? Can we derive system incentives to $\mathrm{CNO}$ from value systems of each $\mathrm{CNO}$ member?

- How can we derive CNO performance indicators definition from CNO Value System?

- How can Value Systems contribute to an efficient trust management? 


\section{REFERENCES}

1. W. M. P. v. d. Aalst, " Making Work Flow: On the Application of Petri nets to Business Process Management," 2001.

2. H, Afsarmanesh, "A framework for Management of Virtual Organization Breeding environments," in PRO-VE. Valencia, Spain, 2005.

3. H. Bouwman, "State Of the Art on Business Models," 2003.

4. G. Brewka, "Reasoning about Priorities in Default Logic Proceedings of the " presented at AAAI National Conference on Artificial Intelligence, 1994.

5. L. Camarinha-Matos and A. Abreu, "Performance indicatores based on collaboration beneficts," in PRO-VE 2005 - Collaborative Networks and Value Creation, Valencia, Spain, 2005.

6. C. R. Cooley, "Cultural Effects in Indian Education:AN APPLICATION OF SOCIAL LEARNING THEORY "Journal of American Indian Education, vol. 17, 1977.

7. Evans, "Performance Measurment and added value of networks," in Collaborative Networked Organizations, Colaborative Networked Organizations L. Camarinha-Matos, Ed. London: Kluwe Academics Publishers, 2004, pp. (147-152).

8. J. Filipe, "The organisational semeiotics normativa paradigma " in Collaborative Networked Organizations, vol. 1, Collaborative networked organizations. A reasearch agenda for emerging business models London: Springer, 2003, pp. 261-272.

9. J. Filipe and K.Liu, "The EDA Model: An Organizational Semiotics Perspective To Norm-Based Agent Design," presented at Agents'2000 Workshop on Norms and Institutions in Multi-Agent Systems, Barcelona, Spain, 2000.

10. T. Gilb, Principies of Software Engineering Management: Addisson-Wesley, 1989.

11. J. Goguen, "Requirements Engineering as the Reconciliation of Technical and Social Issues," in Requirements engineering: social and technical issues, 1994, pp. 162-199.

12. J. Goguen, "Towards a Social, Ethical Theory of Information," in In Social Science Research, Technical Systems and Cooperative Work: Beyond the Great Divide, Georey Bowker, Les Gasser, LeighStar, and W. Turner, Eds.: Erlbaum, 1997, pp. 27-56.

13. J. Goguen, "An Introduction to Algebraic Semiotics with Application to User Interface Design," in Lecture Notes in Artificial Intelligence, Computation for Metaphor, Analogy and Agents, I. C. Nehaniv, Ed.: Springer Verlag, Berlin (DE), 1999, pp. 242--291.

14. J. Goguen, "Semiotics, compassion and value-centered design," 2004.

15. Gordijn, "Business Modelling is not Process Modelling," in ECOMO 200. Salt Lake City, USA: LNCS $1921,2000$.

16. J. Gordijn, J.M. Akkermans, and J. C. v. Vliet, "Value based requirements creation for electronic commerce applications.," presented at In Proceedings of the 33rd Hawaii International Conference On System Sciences, 2000.

17. R. Hartman, "The Measurment of Value," 1973.

18. V. Kartseva, J. Gordijn, H. Akkermans, and "A Design Perspective on Networked Business Models: A Study of Distributed Generation in the Power Industry Sector," presented at 12th European Conference on Information Systems, 2004.

19. B. Katzy, "Value System Redesign," ACM SIGGROUP Bulletin archive, vol. 19, pp. 48-50, 1998.

20. V. Krebs, "Mapping and Measuring Knowledge Creation, Re-Use and Flow," 1998.

21. V. R. Krishnan, "Leader-Member Exchange, Transformational Leadership, and Value System," EJBO Electronic Journal of Business Ethics and Organization Studies, vol. 10, 2005.

22. P.-Y. Liu, "A study based on the Value System for the interaction of the multi-tiered supply chain under the trend of e-business," presented at The 7 th international conference on Electronic Commerce, 2005.

23. M.Jamieson, T. A., and a. T. A. . "Refocusing collaboration technologies in the construction Value System," 1986.

24. D. Mefford and V. Meffortd, "Values Usage Exercise (VUE) A Tool For Raising Values Awareness ConcerningThe Professional - Personal Values Interface

" in Conference on Professional Ethics. WASHINGTON, 1997.

25. M. Porter, Competitive Advantage. : New York: The Free Press, 1985.

26. R. Reiter, "A logic for default reasoning,", Artif. Int., vol. 13, pp. 81-132, 1980.

27. Y. Rezgui, I. Wilson, W. Olphert, and L. Damodaran, "Socio-Organizational issues," presented at PRO-VE, 2004.

28. B. Shneiderman, Designing the User Interface: Strategies for Effective User Interface Interaction, 3rd ed: Addison Wesley Longman, 1998. 
29. L. Soares and S. Pereira, "Tecnologias de colaboração em organizações de I\&D: Uma abordagem por redes sociais.," in Conferencia da Associação Portuguesa de Sistemas de Informação. Bragança, Portugal, 2005.

30. R. Stamper, "Signs, Information, Norms and Systems.," in Signs of Work, Semiosis and Information Processing in Organizations, : in Holmqvist et al. (Eds.)Walter de Gruyter Berlin, New York., 1996.

31. Y.-H. Tan, W. Thoen, and J. Gordijn, "Modeling Controls for Dynamic Value Exchange in Virtual Organizations," 2004.

32. Wiendalh, "Production Networks," presented at Anual Conference of CIRP, 2002. 